Discussion Paper No. 07-040

Computers as Pedagogical Tools in Brazil: A Pseudo-panel Analysis

Maresa Sprietsma

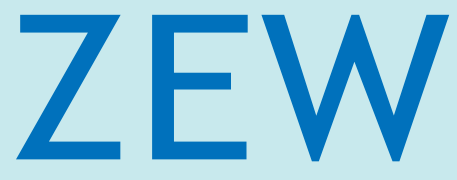

Zentrum für Europäische Wirtschaftsforschung $\mathrm{GmbH}$ Centre for European Economic Research 
Discussion Paper No. 07-040

\title{
Computers as Pedagogical Tools in Brazil: A Pseudo-panel Analysis
}

\author{
Maresa Sprietsma
}

Download this ZEW Discussion Paper from our ftp server:

ftp://ftp.zew.de/pub/zew-docs/dp/dp07040.pdf

Die Discussion Papers dienen einer möglichst schnellen Verbreitung von neueren Forschungsarbeiten des ZEW. Die Beiträge liegen in alleiniger Verantwortung der Autoren und stellen nicht notwendigerweise die Meinung des ZEW dar.

Discussion Papers are intended to make results of ZEW research promptly available to other economists in order to encourage discussion and suggestions for revisions. The authors are solely responsible for the contents which do not necessarily represent the opinion of the ZEW. 


\section{Non technical summary}

Computers and software have been gradually introduced as teaching tools in many countries. Thanks to important public and private investment, the number of schools that have access to computers and internet in the classroom has increased exponentially since the beginning of the nineties. The percentage of schools that have an internet connection has e.g. increased from 5\% in 1996 to over 95\% in the UK and to over $80 \%$ on average in European countries in 2001. In Brazil as well, availability and use of computers and internet in schools represents an important investment and has increased rapidly in recent years. The percentage of teachers that use the computer and internet for pedagogical purposes has increased from 12 to 38 and from 3 to 18 percent respectively between 1999 and 2003. The percentage of schools with a computer laboratory increased from 17 to $35 \%$ in the same period.

The most obvious purpose of introducing computers into the classroom is clearly the promotion of computer literacy, a much-demanded skill on the labour market. However, 'computer assisted instruction' (CAI) or the use of computers as a learning tool for acquiring other cognitive skills, has come more and more under attention as well.

The question we would like to answer empirically is whether the availability and use of computers and internet for schools is effective in improving test scores in maths and reading. We use Deaton's pseudopanel estimator on original repeated cross-section data to estimate the effect of the availability and use of ICT in schools in Brazil on pupils' performance. More precisely, we estimate the effect of the availability of a computer laboratory in school and the use of computers and internet as pedagogical resources by the teacher on $8^{\text {th }}$ grade pupils' test scores.

We find that the availability of a computer laboratory affects test scores negatively in both disciplines and particularly in Maths. Possible interpretations are the existence of a trade-off between investing in a computer lab versus other more effective pedagogical means for schools and, for pupils, between sitting in the lab rather than doing other activities.

But we also find that the use of the internet as a pedagogical resource by the teacher has a significant positive impact on pupils' test scores in both disciplines in Brazil. Therefore, we may conclude that although merely investing in ICT equipment such as computer laboratories does not seem to improve test scores, there seems to be scope for teachers using the internet as a pedagogical resource. Moreover, we should not forget that ICT in schools may also promote computer literacy, a much demanded skill on the labour market. 


\title{
Computers as pedagogical tools in Brazil : a pseudo-panel analysis
}

\author{
Maresa Sprietsma*
}

April 2007

\begin{abstract}
In this paper, we use repeated cross-section data on pupils in Brazil to estimate the effect of the availability and use of computers and internet as pedagogical tools on math and reading test scores. Computers are increasingly commonly used in schools and their effectiveness in improving learning is the subject of many recent evaluations in Europe and the US. We apply the pseudo panel technique to evaluate the effect of variation in the availability and use of computers and internet in Brazilian schools on pupils' test scores.
\end{abstract}

JEL Classification: I20

Keywords: Computers in schools, pupil performance

* Centre for European Economic Research (ZEW)

Department of Labour Markets, Human Resources and Social Policy

L7,1 Mannheim

Tel +49621 1235375

sprietsma@zew.de

Aknowledgements: Thanks are due to Christian Goebel for programming assistance, Alfred Garloff, Anna Vignoles, Vincent Vandenberghe and Thomas Zwick for helpful comments and suggestions. I would like to thank the Ministry of Education in Brazil (INEP) for granting me access to the data and kind help with data formatting. 


\section{Introduction}

Computers and software have been gradually introduced as teaching tools in many countries. Thanks to important public and private investment, the number of schools that have access to computers and internet in the classroom has increased exponentially since the beginning of the nineties. In the US, where this evolution was fastest, the number of students per computer has decreased from 120 to 20 between 1981 and 2000. The percentage of schools that have an internet connection has increased from 5\% in 1996 to over 95\% in the UK and to over 80\% on average in European countries in 2001 (Twining, 2002). In Brazil as well, availability and use of computers and internet in schools represents an important investment and has increased rapidly in recent years. As can be seen in figure 1, the percentage of teachers who use the computer and internet for pedagogical purposes has increased from 12 to 38 and from 3 to 18 percent respectively between 1999 and 2003. The percentage of school with a computer laboratory increased from 17 to $35 \%$ in the same period (SAEB ${ }^{1}$ data).

The most obvious purpose of introducing computers into the classroom is clearly the promotion of computer literacy, a much-demanded skill on the labour market. However, 'computer assisted instruction' (CAI) or the use of computers as a learning tool for acquiring other cognitive skills, has come more and more under attention as well.

According to psychologists, there are several factors that could contribute to better learning when using the computer as a pedagogical tool. Most frequently quoted are the possibility for each student to learn at his or her own pace, to focus on his or her own difficulties rather than to follow a fixed content for the whole class, the possibility of immediate assessment, and resulting increased student motivation (Skinner 1958, Barrow and Rouse 2005). Clearly, there are also potential drawbacks to the use of computers in class. Possible reasons are inadequate software, lack of teacher training and student disruption of learning by side activities on the computer. Indeed, as shown below, there is little evidence that computers improve measured reading or maths skills.

\footnotetext{
${ }^{1}$ SAEB stands for 'Sistema de Avaliação do Ensino Básico' (In English: Evaluation system of basic education). INEP stands for 'Instituto Nacional de Estudos e Pesquisas Educacionais' (In English: National Institute for Educational Studies and Research).
} 
The question we would like to answer empirically is whether the availability and use of computers and internet $\left(\mathrm{ICT}^{2}\right)$ for schools is effective in improving test scores in maths and reading. The empirical literature on this topic is recent and causal evaluations are few. Surveys from the literature of the nineties (e.g. Liao 1992, Kirkpatrick and Cuban 1998) conclude to a moderately positive effect of CAI on cognitive outcomes but warn for the lack of proper identification strategies in many of these studies.

The first attempts to actually identify a causal effect of the use of ICT in the classroom are from recent years. Machin et al. (2005) quote Angrist and Lavy (2002) to be the first paper to use a more reliable methodology to study the effect of ICT in schools. We can distinguish two types of measures of ICT availability and use in this literature. First there are authors studying the use of specific software in the classroom. Another branch of research focuses on computer use and availability as a result of changes in funding.

Two papers evaluating the effect of a specific reading software (FastForWord) in the US find no significant impact on reading performance (Rouse et al. 2004, Borman and Rachuba 2001). The identification is based on random assignment of pupils to the computer assisted reading program. To the contrary, the original paper by Banerjee et al.(2004) on a randomised experiment in India does find positive effects of using software for teaching Mathematics. During the experiment, randomly selected schools had access to educational software for learning Mathematics (2 hours of shared use per week per child) in Indian slums. The authors find an important positive impact of this computer assisted learning program on Mathematics test scores. However, such experimental evidence is hard to generalise and to compare to other results as experiments by their nature take place in a very specific environment.

Of the four papers that try to estimate a causal effect of the use of computers in general, which corresponds better to our approach, three yield insignificant or negative effects of increased computer use on test scores. Goolsbee and Guryan (2004), using exogenous variation in funding for internet access in schools in the US, find no evidence of any effect of the availability of additional internet access on student performance. Angrist and Lavy (2002), using random additional funding for ICT in Israel find no significant effect on $8^{\text {th }}$ grade $^{3}$ maths and reading test scores, and a significant negative impact on $4^{\text {th }}$ grade maths scores. Leuven et al. (2004),

\footnotetext{
${ }^{2}$ Information and communication technology

${ }^{3} 8^{\text {th }}$ graders are about 14 years old, $4^{\text {th }}$ graders 10.
} 
based on a regression discontinuity design, also find a negative effect of investing in educational software on pupil reading and maths test scores in disadvantaged primary schools in the Netherlands. These papers conclude that computer-based instruction methods seem less effective than traditional ones.

Machin et al. (2005) use a change in the rules on ICT investment in English schools in 2001 to identify the effect of computers in the classroom and teacher ICT training on math and reading test scores. They find a positive effect of additional ICT investment on pupil performance but only for reading and science test scores (not in maths) in primary schools where the largest investments where made.

In this paper we exploit rich repeated cross-section data from Brazil to provide pseudo-panel evidence on the impact of the availability and use of computers in schools on $8^{\text {th }}$ graders reading and math test scores. To our knowledge no study of the impact of computer and internet use in school on pupil performance exists as yet for Brazil. Moreover, the important regional diversity in educational resources in this country provides a suitable basis for the construction of our pseudo-panel cohorts. The estimator we use is Deaton's errors-in-variables estimator for a small number of time periods (Verbeek and Nijman 1993).

We base our measures of the availability and use of computers and internet in the school on answers to the following questions asked to schools (a) and teachers (b) :

- Does the school have a computer laboratory? (a)

- Do you use computers available for pupils in school as a pedagogical resource?(b)

- Do you use internet access in school as a pedagogical resource?(b)

The pseudo-panel technique is used to limit the endogeneity problem that is likely to occur at the school level, as unobserved characteristics of the schools may be correlated both with pupils performance and ICT availability.

We find that the availability of a computer lab in school is significantly negatively correlated with test scores both in maths and reading. The proportion of teachers using the internet as a pedagogical resource is positively correlated with test scores in both disciplines whereas the use of only computers has a very small but significant positive effect. 
The paper is organised as follows. In section 2 we explain how we constituted our dataset. In section 3 we present our estimation strategy and explain the pseudo-panel methodology. Section 4 contains our findings and interpretation of results.

\section{The dataset ${ }^{4}$}

The data we use are the SAEB micro data, collected by the Brazilian ministry of Education (INEP) ${ }^{5}$. In a set-up similar to PISA (OECD), questionnaires were given out to a representative sample of schools and pupils in Brazil every two years since 1995. The sample is representative of the national and regional pupil population. Questionnaires were filled in by samples of teachers, school directors, and pupils every two years. They contain a large number of questions for the teachers and the director such as on their education, wage, experience, teaching methods, school infrastructure. The pupil questionnaire investigates parents income, education, home resources and individual characteristics of the pupil such e.g. as gender or hours of homework.

The participation rate of schools is close to $100 \%$. Samples of pupils in each wave from three different grades $\left(4^{\text {th }}, 8^{\text {th }}\right.$ and 11th grade) took a Mathematics, Portuguese, Science, History or Geography test. The tests employ a large number of items (150 per grade per subject) and are analysed in accordance with the Item Response Theory models. Test scores are comparable between different grades and through time. We use only the Mathematics and Portuguese test scores.

Each pupil only took a test in only one discipline. This implies we have as many pupil datasets as there are grades times disciplines for each year. New samples of schools and pupils are drawn each wave, and sample size increases over time.

The questions and the form ${ }^{6}$ of the proposed answers tend to change between the first years of data collection, making it impossible to compare responses for many important variables. We therefore use these data for three years only: 1999, 2001 and 2003.

\footnotetext{
${ }^{4}$ This section is based on Guimaraes De Castro, 2001

5 SAEB stands for 'Sistema de Avaliação do Ensino Básico' (In English: Evaluation system of basic education). INEP stands for 'Instituto Nacional de Estudos e Pesquisas Educacionais' (In English: National Institute for Educational Studies and Research).

${ }^{6}$ Answers to the same question may e.g. have different categories in different years.
} 
We complement this dataset with extra information on schools and policy from the 'Censo Escolar' database ${ }^{7}$. The latter contains detailed yearly panel data on all Brazilian schools, of which the sub sample that participated to SAEB. We use only the public schools from the sample because they constitute a more homogenous group of pupils and schools and because the majority of pupil attends public schools. It is unfortunately not possible to analyse the private schools separately because the number of observations is too low to apply our pseudo-panel estimator.

\section{The model}

\subsection{The main idea of pseudo-panel estimation}

In order to estimate the effect of the use of computers and internet on student test scores, we use an education production function where test scores are explained by a series of 'input' variables:

$$
\begin{aligned}
& \operatorname{SCORE}_{i j t}=C+\sum_{k=1}^{N_{X}} \alpha_{k} X_{k}+\beta_{1} \cdot \text { COMPLAB }_{j t}+\beta_{2} \cdot \text { COMPUSE }_{j t} \\
& +\beta_{3} . \text { INTERNETUSE } \\
& j t
\end{aligned}
$$

where $D_{t}$ are dummies for the years 2001 and 2003. Indices $\mathrm{i}, \mathrm{j}$ and $\mathrm{t}$ respectively stand for pupil $\mathrm{i}$ in school $\mathrm{j}$ at time t. $N_{X}$ is the number of control variables $\mathrm{X}$.

The explanatory variables of interest are the presence of a computer laboratory in the school (COMPLAB), and the use of computers only or of the internet by the teacher as pedagogical tools (COMPUSE, INTERNETUSE).

In the education production function literature, pupil performance is assumed to be a function of a set of educational 'input' variables (Becker, 1976). Three types of inputs are typically distinguished: individual characteristics, family background, and school variables (Todd and Wolpin, 2003). The family background variables that we include are the number of books at home (NBBOOKS), and the possession of a computer at home (COMPATHOME). Due to a collinearity issue at the aggregate level, we cannot include more home characteristics. Indeed, possession of a car by the family and mother education are very strongly correlated with COMPATHOME, as can be seen in Table 1 . We do not include mother

\footnotetext{
${ }^{7}$ In English : School Census, also kindly made available by INEP.
} 
education as there is much less variation in the proportion of educated mothers between regions than in the proportion of households that have a computer at home.

School resources are taken into account with the presence of a science laboratory (SCIENCELAB), a library (LIBRARY), sport facilities (SPORT), as well as class size (STRATIO). These variables are from Censo Escolar. Teacher characteristics are measured by the percentage of teachers that went to university (UNIVPROF) and that attended some form of on-the-job training in the last two years (ONTHEJOB). The organisational quality of the school are taken into account with the director's wage (WAGEDIR).

We also include a measure of the policy activity in the educational sector, as a proxy for the amount of educational policy that is going on in a given State. More precisely, we use the percentage of schools that have participated in a library support policy (LIBRARYPOL), in a pupil transport policy (TRANSPORTPOL), and in an educational television programme (EDUCTVPOL). These policies are among the broadest applied educational policies in Brazil.

All the ICT related variables are subject to an endogeneity problem in this equation. In effect, both the presence of computer laboratory and computer and internet use by the teacher could be related to e.g. the openness of the director and teachers to new teaching methods, their experience with ICT and potentially other unobserved characteristics that in turn affect test scores. Omitting these factors will most likely lead to biased estimates.

Unfortunately, we do not have data on the same teachers and pupils for several years. Each two years, new samples of schools and pupils were drawn to complete the questionnaires. Therefore we cannot apply fixed or random effects estimation methods to address the endogeneity problem.

Hence, the pseudo-panel technique allows us to estimate our model using several years of repeated cross-section data. The idea is to group individuals into so-called 'cohorts' (or pseudo-cohorts) based on permanent observable characteristics. These cohorts are created on the same criteria in each wave. If e.g. the criterion for being in a same cohort is place of birth then we could create groups of people born in the same municipality. These groups of 'similar' people by construction exist in all years for which we have data. We therefore have a panel of pseudo-cohorts of people. Pseudo-panel consists in using the created pseudo-cohorts in place of individuals in a fixed effects panel estimation (Deaton 1985). 
We take the mean values of both the dependent and the explanatory variables by cohort and estimate the equation by fixed effects (through the inclusion of cohort dummies). The variation in ICT use across cohorts and over time allows us to identify the impact of the availability and use of computers on pupils test scores.

The estimated equation is thus:

$$
\begin{aligned}
& \overline{\operatorname{SCORE}_{C t}}=\sum_{i}^{N_{X}} \alpha_{i} \cdot \overline{X_{i C t}}+\beta_{1} \cdot \overline{\operatorname{COMPLAB}}_{C t}+\beta_{2} \cdot \overline{\text { COMPUSE }_{C t}} \\
& +\beta_{3} \cdot \overline{\text { INTERNETUSE }} \\
& C t
\end{aligned}
$$

Where $D_{C}$ are dummy variables for all the cohorts, $N_{C}$ is the number of cohorts, and $\bar{X}$ stands for the cohort mean of $\mathrm{X}$.

Time constant characteristics of the cohorts are removed when estimating the pseudo-panel using fixed effects in the same way a panel fixed effects estimation eliminates individual constant characteristics. Endogeneity is hereby reduced in two ways: firstly data are aggregated to cohort level, meaning that unobserved school effects only remain an issue if they also exist at cohort level. Moreover, all time-constant cohort characteristics are removed by the inclusion of the cohort dummies.

Changes over time in the unobserved characteristics of the cohorts due to e.g. migratory movements across states or educational policy may be a problem as they will not be removed with the inclusion of the cohort fixed effects. To limit the scope for remaining time-varying cohort characteristics to bias our results we include some educational policy variables to capture the degree of political activity of the state in the educational sector. The political activity of the region in the educational sector is captured by three policy variables: the percentage of schools participating in a policy financing a school library (LIBRARYPOL), pupil transport to school (TRANSPORTPOL) and a television based educational program (EDUCTVPOL) ${ }^{8}$.

\subsection{Creating the cohorts}

Like in panel data, observed cohort characteristics that do not vary over time will also be eliminated from the estimation. It is therefore important to

\footnotetext{
${ }^{8}$ Also from Censo Escolar
} 
create cohorts such that there is enough inter-cohort variation as well enough inter-temporal variation (for each cohort) in the variables we are interested in. This is true for both the dependent and the explanatory variables and in particular for the explanatory variable of interest: classroom computers or internet. As a result, it is not an option to construct the cohorts based on variables that are independent of the dependent and explanatory variables. If we did so, there would be no inter-cohort variation and identification would not be possible.

Moreover, the selection of cohort members should be as homogenous as possible over time (since we want them to be comparable). This implies that we use characteristics of the individuals that do not change over time.

Finally we face a trade-off as to cohort size. Creating less but larger cohorts implies that we will have more reliable cohort means versus a smaller number of observations for each time period, the reverse being true for the creation of more but smaller cohorts. This is a constraint on the number and type of categorical variables that will be used to create the cohorts.

Based on these observations, we choose to create our cohorts based on the 'Unidades de Federaçao' ( 27 Brazilian states), gender and ethnic origin of pupils (white or non-white). These variables are observed for all individuals and should provide considerable inter-cohort variation in control and main explanatory variables. In effect, the Brazilian education system is based on the States which creates institutional variation in the education system. Moreover, there is important diversity in pupil and school characteristics between states due to high regional inequalities in Brazil. Ethnic origin is a permanent individual characteristic and captures an important set of unobserved socio-economic characteristics in Brazil. We therefore expect test scores and explanatory variables to be correlated with the ethnic origin of a pupil. Finally, gender is a permanent individual characteristic that generates variation in test scores and random variation in explanatory variables. These three criteria for grouping individuals yield a total number of 108 cohorts of on average 100 pupils for each year (We refer to Table 2 for details on cohort size).

Tables 3 and 4 present descriptive statistics at cohort level. First of all we note that there is substantial variation in the explanatory variables between cohorts, and over time. The proportion of schools with a computer laboratory for instance varies between 0 and 86 percent over cohorts, whereas the proportion of teachers using the internet as a pedagogical tool goes from 0 to 47.6 percent. We have plotted the math and reading test 
scores against the main explanatory variables to check for outliers that could drive our results because of the small number of observations (108 each year). This does not seem to be the case, the correlations seems to exist (according to the plots) independently of outliers.

\subsection{Errors of measurement}

The use of the pseudo-cohorts is an answer to some of the endogeneity problems in repeated cross-section data, but it generates a measurement error issue. In effect, because we do not observe all individuals of a given cohort, the sample cohort means are imperfect measures of the real cohort means: $\overline{X_{C}}=\overline{X_{C}^{*}}+v$ where $\overline{X_{C}}$ is the real cohort mean and $\overline{X_{C}^{*}}$ the sample cohort mean.

The larger the cohort size, the more reliable the sample mean should be. As a consequence, it is common practice when using pseudo-panel data to weigh the sample cohort means with the square root of cohort size before estimating (see e.g. Propper et al. 2001, Taylor 2002).

However, this is not sufficient to solve the measurement error problem and does not fully apply Deaton's formula. In effect, Deaton's pseudo-panel formula is an 'errors-in-variables' estimator. It corrects for errors of measurement in the cohort means and for potential correlation between these errors of measurement in both the dependant and the explanatory variables. If $\mathrm{Y}$ and $\mathrm{X}$ are both imperfect measures of their true value, and the errors of measurement are correlated, the estimated coefficient between $\mathrm{Y}$ and $\mathrm{X}$ will contain the correlation of errors. This occurs in addition to the bias generated by the presence of the measurement error itself. Since the measurement errors and their correlation do not decrease with the number of observations, the OLS coefficient is inconsistent ${ }^{9}$. The idea of Deaton's pseudo panel estimator is to remove the part of the variation that is due to the presence and correlation of the errors of measurement from the estimated coefficient between the dependant and explanatory variables.

Moreover, we only have three time periods in our dataset. Following Verbeek and Nijman (1993), this implies that Deaton's original estimator could be inconsistent and we thus apply their pseudo-panel estimator for a small number of time periods ${ }^{10}$. Since the 'Verbeek and Nijman estimator' is

\footnotetext{
${ }^{9}$ Please see annex 1 for details.

${ }^{10}$ The Verbeek and Nijman estimator is very similar to Deaton's estimator, details can be found in the annex.
} 
merely an adaptation of Deaton's estimator to limited numbers of time periods we refer to it as the 'Deaton estimator for a small number of time periods'. This will be our third estimation, again using specification (3.2) but applying Deaton's pseudo-panel estimator for a small number of time periods.

In order to compute a confidence interval for this estimator we need bootstrapping, as no formula for the variance is available. As a consequence we estimate all three specifications using the bootstrap technique, to ensure comparability of results. Bootstrapping consists of randomly drawing a small percentage of cohorts ( $10 \%$ here) to be excluded from the estimation and compute the estimates. We repeat this procedure 500 times and present the median of the obtained estimates as well as the 2.5 and 97.5 percentiles that constitute the $95 \%$ confidence interval.

\section{Empirical results}

\subsection{Results}

The Deaton estimates for a small number of time periods (Verbeek and Nijman 1993) are presented in Table 5. Our main finding is that the proportion of teachers who use the internet as a pedagogical resource has a significant positive impact on test scores in both disciplines of 18.37 (Portuguese) and 8.9 (Maths) percent of a standard deviation in test scores. The use of computers as a pedagogical resource has a small but significant positive impact on test scores of 3.1 percent of a standard deviation in test scores in both disciplines. Moreover, the proportion of pupils that have a computer lab in the school significantly affects Maths test scores downwards by 33.5 versus 12.7 percent of a standard deviation in test scores for Portuguese.

Our results are in line with some previous results in the literature such as Leuven et al. (2004) and Angrist and Lavy (2002), who also find significant negative effects of increased ICT availability and use in schools especially on Mathematics test scores. These authors conclude that computer related instruction methods seem less effective than other instruction methods especially for learning Mathematics. However; in this paper, in those schools where there is no lab there are on average 1.4 computers, which does not allow for software based teaching in a class where each pupil has a computer. Moreover, the finding that cohorts where more schools have computer labs perform less well cannot be explained by the lack of controls for school resources. Indeed, the most well-off schools should have the best 
ICT equipment, thus the coefficient should be biased upwards by such resource effects.

Possible alternative explanations could be that the computer lab facilities are acquired instead of other school materials that are more favourable to learning. The schools with a lot of labs would have made the wrong investment choices. In addition, pupils in schools with a computer lab could spend a lot of time there chatting or playing instead of doing other more constructive activities. The proportion of schools that have a computer lab is significantly negatively correlated with the average number of hours of homework done per week (the correlation coefficient is of -0.12 at cohort level).

The positive effect of internet use as a pedagogical tool points to a potential for using internet as a teacher resource. Considering the low level of access to internet in Brazil, if teachers gain access to internet thanks to the school then all the information and ideas only become available with the connection of the school which could be reflected in test scores. If to the contrary teachers already have access to the internet outside school, the value added from a school connection is limited. Moreover, the way computers are used is likely to be very important to their effectiveness in improving student learning. Unfortunately this information is not available in our data.

Although the presence of a computer lab appears detrimental to the acquisition of Maths and reading skills, we should keep in mind that computers may also contribute to acquiring other useful skills which we do not test. Know-how of computers and software has an intrinsic value on the labour market and may in itself justify investment in computer labs.

Only two of the other school resource indicators significantly affect test scores: the availability of a school library and of a science laboratory. The percentage of schools that have a library increases average test scores by between 10 and 14.5 percent of a standard deviation in test in Portuguese and Maths scores respectively. Teacher and director characteristics have a significant impact except the proportion of teachers that obtained a university degree that is not related to test scores. The proportion of teachers doing on-the-job training is correlated significantly positively with test scores both disciplines as well as the average director wage. The director's wage can be considered a proxy for the overall level of resources of the school therefore we expect a positive coefficient. As for the home resources, the percentage of pupils that have a computer at home has a significant positive effect of between 47.6 and 93.3 test score points whereas the 
average percentage of pupils that have more than a hundred books at home is not significantly related to test scores. The large size of the coefficient of the percentage of pupils that have a computer at home is not entirely unexpected. It is the only indicator of wealth and considering the large variation in income across Brazil one expects it to explain an important share of the differences in educational performance. Of the three included policy variables, only the proportion of schools that participated to the educational television policy has a significantly positive effect on test scores in both disciplines.

As a benchmark, we also present the weighted and unweighted pseudopanel estimates (specification 3.2) in Tables 6 and 7 for Portuguese and Maths test scores respectively. These estimates do not correct for errors of measurement, it is merely a panel of pseudo-cohorts that have been weighted or not with the square roots of cohort sizes. These coefficients are overall quite different (though of the same sign) from the more reliable Deaton estimates and relatively less significant. In particular, the COMPATHOME and COMPUTERLAB variables are not significantly different from zero in this specification. The observed change in the parameter estimates points to the existence and correlation of cohort average measurement errors and justify the use of the Deaton estimator. Moreover, we also observe significant differences between the weighted and unweighted pseudo-panel estimates. This does not come as a surprise, as the cohort sizes are very different and estimates can be expected to change when using them as weights.

\subsection{Robustness}

Teachers making use of the computer to teach may also make some specific pedagogical choices or are simply more motivated. This could lead to over or underestimation of the effect of the use of computers and the internet. To test for this possibility, we include in a second specification some control variables that relate to the pedagogical methods used by the teacher. In Portuguese, we add measures for letting the pupils work on a project in class (PROJECT), doing exercises from the textbook (EXERCISES), copying material from the blackboard or textbook (COPY), reading newspaper articles (NEWSPAPER) or text analysis (ANALYSIS). These dummy variables (aggregated to cohort level) equal one if the teacher claims to use a given method at least once a week. In mathematics, we add measures for solving problems in class (SOLVEPB), for relating the mathematical materials to topics of pupil interest (INTEREST), and for practicing calculus (CALCULUS). 
Although these are imperfect measures of teacher pedagogical choices, the reaction of the coefficients of TEACHUSESCOMP and TEACHUSESNET to their inclusion can still tell us something about their robustness. We can only include these additional control variables for the years 2001 and 2003, as they are not available in the 1999 dataset. Running our bootstrap program on only two years of data is a strong constraint on the data. Remaining variation is very limited and collinearity problems arise between the aggregated variables. As a result, none of the coefficients are significant, and we have to remove TEACHERUSESCOMP from the estimated equation because of collinearity with COMPUTERLAB.

Including teaching methods in specification (3.2) on 2001-2003 data does not alter our main conclusions (Tables 8 and 9). The effect of a computer lab in the school as well as internet use by the teacher on pupil's test scores remains of the same sign and magnitude (estimates are higher in this specification). Although the additional variables cannot be expected to capture all unobserved teacher characteristics we may at least exclude that the measured effect of computer use is due to teachers claiming to use computers more may also (claim to) use some other teaching methods more often.

\section{Conclusion}

We use Deaton's pseudo-panel estimator on original repeated cross-section data to estimate the effect of the availability and use of ICT in schools in Brazil on pupils' performance. More precisely, we estimate the effect of the availability of a computer laboratory in school and the use of computers and internet as pedagogical resources by the teacher on $8^{\text {th }}$ grade pupils' test scores. We find that the availability of a computer laboratory affects test scores negatively in both disciplines and particularly in Maths. Possible interpretations are the existence of a trade-off between investing in a computer lab versus other more effective pedagogical means for schools and, for pupils, between sitting in the lab rather than doing other activities.

The impact of the use of the internet by the teacher as a pedagogical resource by the teacher has a significant positive impact on pupils' test scores in both disciplines in Brazil whereas the use of computers only has a very small but significant positive effect. These results are in line with some recent studies in Europe and the US that find non significant or negative effects of the availability of ICT in schools, especially on mathematics test scores. 
Therefore, we may conclude that although merely investing in ICT equipment such as computer laboratories does not seem to improve test scores, there seems to be scope for teachers using the internet as a pedagogical resource. Moreover, we should not forget that ICT in schools may also promote computer literacy, a much demanded skill on the labour market. The ineffectiveness of ICT in schools as a means to learn Maths and reading is therefore not a reason to ban ICT from schools. 


\section{ANNEX 1}

\section{Deaton's pseudo-panel estimator}

The principle of the pseudo-panel estimator is to perform fixed effects analysis with pseudo-cohorts of individuals. The created pseudo-cohorts of individuals are observed in each wave. Means of the explanatory and dependent variable are used in the estimation, instead of the individuals observations which are not available for more than one year.

However, the sample cohort means are imperfect measures of the true cohort means: $\bar{X}_{C}=\bar{X}_{C}^{*}+v$ and $\bar{Y}_{C}=\bar{Y}_{C}^{*}+u$ where $\bar{X}_{C}$ and $\bar{Y}_{C}$ are the sample cohort means and $X_{C}^{*}$ and $Y_{C}^{*}$ the real cohort means. If $v$ and $u$ are correlated an OLS regression of $\mathrm{Y}$ on $\mathrm{X}$ will yield inconsistent estimates. We thus need to correct for these "errors of measurement" of the cohort means, that appear due to the aggregation at cohort level.

The "error of measurement" can be approximated by taking the average difference between the individual values of a variable and its cohort mean : $X_{i C}-\overline{X_{C}}$.

The solution consists in using the correlation matrix of these errors of measurement, computed using the individual and cohort mean data, to correct the $\mathrm{X}^{\prime} \mathrm{X}$ matrix.

Hence the form of the estimator:

$$
\beta_{\text {DEATON }}=\left(\overline{X_{C}} \cdot \overline{X_{C}}-N_{C} \cdot N_{T} \cdot \Sigma\right)^{-1} \cdot\left(\overline{X_{C}} \cdot \overline{Y_{C}}-N_{C} \cdot N_{T} \cdot \sigma\right)
$$

Where $\overline{X_{C}}$ is the matrix of cohort means for all $\mathrm{X}$ and all cohorts, $N_{C}$ is the number of cohorts, $N_{T}$ is the number of time periods. $\Sigma$ is the variancecovariance matrix of measurement errors in the explanatory variables: $X_{i C}-\overline{X_{C}}$ for all different $\mathrm{X}$ variables, $\sigma$ the covariance matrix of errors in $\mathrm{Y}$ and in $\mathrm{X}:\left(Y_{i C}-\overline{Y_{C}}\right)$ and $\left(X_{i C}-\overline{X_{C}}\right)$..

Note that when sample size increases, $\Sigma$ does not decrease: errors may still be correlated even if many individuals. However, $X^{\prime} X$ becomes relatively larger, making the correction less important.

Verbeek and Nijman (1993) show that for a small number of time periods, Deaton's estimator is not consistent. The correction matrix Sigma should be pre-multiplied by a factor proportional to the number of available cross- 
sections. This amounts to giving less weight to the correlation of the errors (Sigma) term when there are less time periods. This seems intuitively reasonable as the correction matrix should be more reliable the more time periods we can rely on to calculate it.

$\beta_{\text {Vand }}=\left(\overline{X_{C}} * \overline{X_{C}}-\frac{N_{T}-1}{N_{T}} \cdot N_{C} \cdot N_{T} \cdot \Sigma\right)^{-1} \cdot\left(\overline{X_{C}} \cdot \overline{Y_{C}}-\frac{N_{T}-1}{N_{T}} \cdot N_{C} \cdot N_{T} \cdot \sigma\right)$

We have three time periods, hence $\frac{N_{T}-1}{N_{T}}=\frac{2}{3}$ and

$\beta_{\text {Vand }}=\left(\overline{X_{C}} * \overline{X_{C}}-2 \cdot N_{C} \cdot \Sigma\right)^{-1} \cdot\left(\overline{X_{C}} * \overline{Y_{C}}-2 \cdot N_{C} \cdot \sigma\right)$ 


\section{ANNEX 2}

\section{Steps in estimation procedure}

In short, we take the following steps to compute the errors-in-variables estimator:

1. Create the sample error of measurement of the cohort means for all explanatory variables and the dependant variable using the individual data merged with the cohort level data.

$e_{i}=X_{i C}-\bar{X}_{C}$ for all $\mathrm{X}$

$e_{Y}=Y_{i C}-\overline{Y_{C}}$

where $X_{i C}$ represents the values of explanatory variable $\mathrm{X}$ for each individual $\mathrm{i}$ in cohort $\mathrm{C}$ and $\bar{X}_{C}$ the sample cohort mean of variable $\mathrm{X}$.

2. Compute the covariance matrix of these errors of measurement for all explanatory variables:

$\Sigma$ of size $N_{X} \times N_{X}$ where $N_{X}$ is the number of explanatory variables:

$\Sigma=\left[\begin{array}{ccccc}\operatorname{Var}\left(e_{1}\right) & & & & \\ \operatorname{Cov}\left(e_{2}, e_{1}\right) & \operatorname{Var}\left(e_{2}\right) & & & \\ \operatorname{Cov}\left(e_{3}, e_{1}\right) & \operatorname{Cov}\left(e_{3}, e_{2}\right) & \operatorname{Var}\left(e_{3}\right) & & \\ . & . & . . & . . & \\ \operatorname{Cov}\left(e_{N_{X}}, e_{1}\right) & \operatorname{Cov}\left(e_{2 N}, e_{2}\right) & \operatorname{Cov}\left(e_{2}, e_{3}\right) & . . & \operatorname{Var}\left(e_{N_{X}}\right)\end{array}\right]$

3. Compute the covariance of errors in $\mathrm{Y}$ and in $\mathrm{X}$ : $\sigma$ of size $N_{X} \times 1$ $\sigma=\left[\begin{array}{c}\operatorname{Cov}\left(e_{Y}, e_{1}\right) \\ \operatorname{Cov}\left(e_{Y}, e_{2}\right) \\ \operatorname{Cov}\left(e_{Y}, e_{3}\right) \\ . \cdot \\ \operatorname{Cov}\left(e_{Y}, e_{N_{X}}\right)\end{array}\right]$

4. Calculate the estimator according to the formula presented in Annex 1. 5. Repeat these steps with another sample 500 times 
6. Present the median and the 95 percent confidence interval of the obtained coefficients. 
Figure 1: Evolution of ICT use in Brazilian schools, Percents of total, Portuguese.

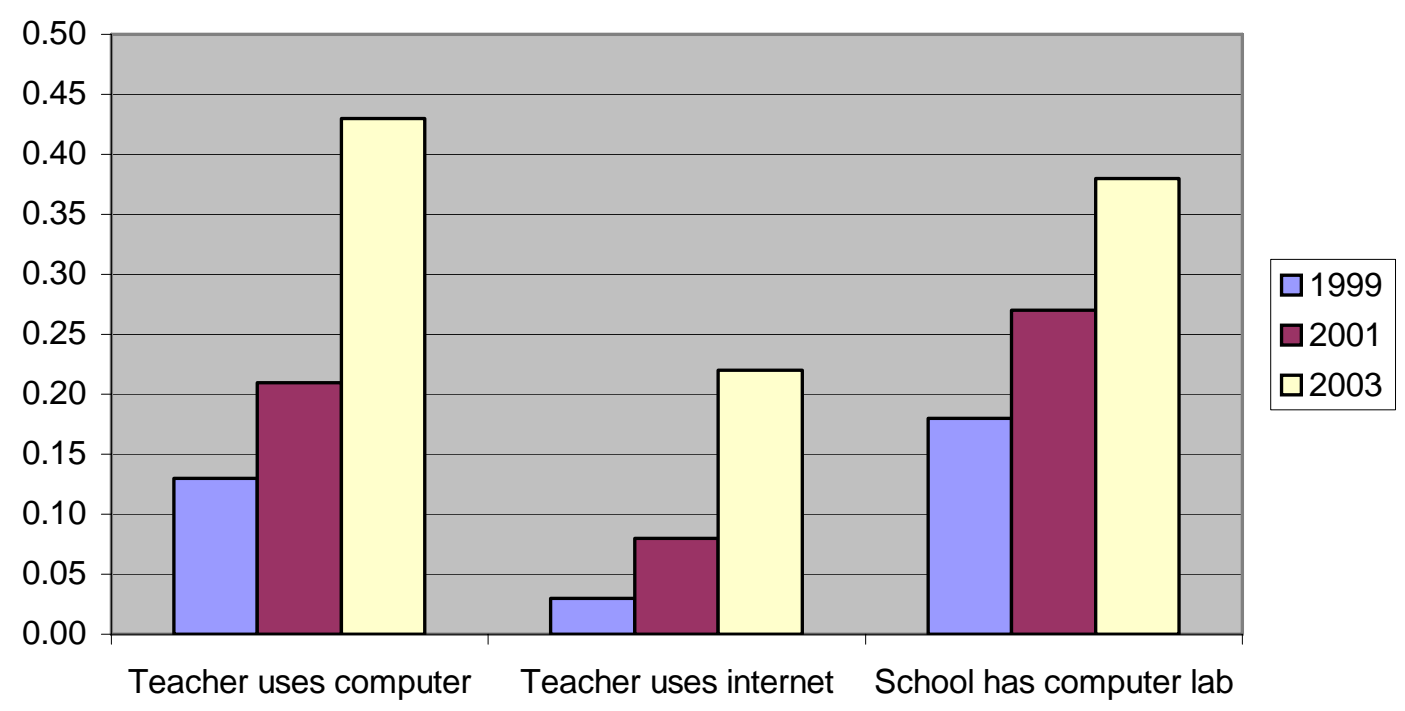


Table 1 : Correlation coefficients of the home resources variables (cohort means)

Parents have a car Mother education Nbbooks Compathome

Parents have a car

Mother education

$0.33^{* * *}$

1

Number of books

0.09

0.06

1

Compathome

$0.72 * * *$

$0.58 * * *$

$-0.07$

1

Table 2 : Cohort sizes, by year and discipline

\begin{tabular}{l|ccc|ccc}
\hline & \multicolumn{3}{|c|}{ Portuguese } & \multicolumn{3}{c}{ Maths } \\
\hline Cohort size & 1999 & 2001 & 2003 & 1999 & 2001 & 2003 \\
\hline Min & 31 & 43 & 30 & 30 & 37 & 23 \\
Max & 242 & 596 & 618 & 226 & 600 & 604 \\
Average & 102.5 & 269.8 & 219.5 & 101.8 & 263.8 & 218.6 \\
\hline
\end{tabular}


Table 3 : Descriptive statistics (cohort means), all years pooled, Mean and Std Deviation

\begin{tabular}{l|cc|l|cc}
\hline & Portuguese & & \multicolumn{2}{c}{ Maths } \\
\hline Test scores & 500 & 100 & Test scores & 500 & 100 \\
\hline Home resources & & & Home resources & & \\
Number of books at home & 0.33 & 0.11 & Number of books at home & 0.34 & 0.12 \\
Computer at home & 0.12 & 0.09 & Computer at home & 0.12 & 0.09 \\
\hline ICT availability and use & & & & & \\
Teacher uses computer only & 0.15 & 0.07 & Teacher uses computer only & 0.15 & 0.06 \\
Teacher uses internet & 0.11 & 0.11 & Teacher uses internet & 0.10 & 0.10 \\
School has computer lab & 0.27 & 0.17 & School has computer lab & 0.27 & 0.17 \\
\hline School resources & & & School resources & & \\
School has library & 0.76 & 0.16 & School has library & 0.76 & 0.17 \\
Student teacher ratio & 35.11 & 3.60 & Student teacher ratio & 35.12 & 3.52 \\
School has science lab & 0.24 & 0.20 & School has science lab & 0.24 & 0.20 \\
School has sports facilities & 0.67 & 0.17 & School has sports facilities & 0.67 & 0.17 \\
\hline Teacher and director characteristics & & & & \\
Wage director & 6.91 & 1.52 & Wage director & 6.90 & 1.52 \\
Teacher has university degree & 0.83 & 0.15 & Teacher has university degree & 0.78 & 0.19 \\
Teacher did on-the-job training & 0.78 & 0.12 & Teacher did on-the-job training & 0.74 & 0.12 \\
\hline Regional Educational policy & & & & & \\
Library policy & 0.38 & 0.17 & Library policy & 0.38 & 0.18 \\
Transport policy & 0.13 & 0.10 & Transport policy & 0.13 & 0.10 \\
Educ. television policy & 0.72 & 0.14 & Educ. television policy & 0.72 & 0.14 \\
\hline Teaching methods & & & & \\
Exercises & 0.68 & 0.17 & Exercises & \\
Newspaper & 0.56 & 0.16 & Newspaper & 0.87 & 0.10 \\
Grammar using newspaper & 0.55 & 0.10 & Complex & 0.25 & 0.13 \\
Student project & 0.58 & 0.12 & Memory & 0.63 & 0.17 \\
Reading & 0.61 & 0.13 & Interest & 0.67 & 0.11 \\
Grammar using poems & 0.56 & 0.10 & Solve problems & 0.62 & 0.10 \\
Text analysis & 0.82 & 0.08 & Train calculus & 0.84 & 0.09 \\
& & & & 0.13 \\
\hline
\end{tabular}


Table 4 : Descriptive statistics (cohort means), all years pooled, minimum and maximum

\begin{tabular}{l|cc|l|cc}
\hline \multicolumn{2}{c}{ Portuguese } & \multicolumn{3}{c}{ Maths } & \\
\hline & Min & Max & & Min & Max \\
\hline Test scores & 296.63 & 756.67 & Test scores & 312.96 & 764.33 \\
\hline Home resources & & & & & \\
Computer at home & 0.00 & 0.41 & Computer at home & 0.00 & 0.41 \\
Number of books at home & 1.15 & 1.91 & Number of books at home & 1.18 & 1.98 \\
\hline ICT availability and use & & & & & \\
Teacher uses computer only & 0.02 & 0.35 & Teacher uses computer only & 0.06 & 0.36 \\
Teacher uses internet & 0.00 & 0.57 & Teacher uses internet & 0.00 & 0.47 \\
School has computer lab & 0.00 & 0.86 & School has computer lab & 0.00 & 0.86 \\
\hline School resources & & & & & \\
School has library & 0.31 & 1.00 & School has library & 0.28 & 1.00 \\
Student teacher ratio & 25.54 & 43.72 & Student teacher ratio & 25.89 & 43.5 \\
School has science lab & 0.00 & 0.79 & School has science lab & 0.00 & 0.83 \\
School has sports facilities & 0.30 & 1.00 & School has sports facilities & 0.28 & 1.00 \\
\hline Teacher and director characteristics & & & & \\
Wage director & 4.38 & 11.82 & Wage director & 4.40 & 12.05 \\
Teacher has university degree & 0.42 & 1.00 & Teacher has university degree & 0.25 & 1.00 \\
Teacher did onthejob training & 0.38 & 0.99 & Teacher did onthejob training & 0.40 & 1.00 \\
\hline Regional Educational policy & & & & & \\
Library policy & 0.00 & 0.85 & Library policy & 0.00 & 0.91 \\
Transport policy & 0.00 & 0.48 & Transport policy & 0.00 & 0.45 \\
Educ tv policy & 0.30 & 1.00 & Educ tv policy & 0.36 & 1.00 \\
\hline Teaching methods & & & & 0.53 & 1.00 \\
Exercises & 0.28 & 1.00 & Exercises & 0.17 & 0.94 \\
Newspaper & 0.21 & 0.89 & Newspaper & 0.40 & 0.90 \\
Grammar using newspaper & 0.30 & 0.82 & Complex & 0.39 & 0.86 \\
Student project & 0.32 & 0.96 & Memory & 0.50 & 1.00 \\
Reading & 0.28 & 0.92 & Interest & 0.91 \\
Grammar using poems & 0.34 & 0.82 & Solve problems & & \\
Text analysis & 0.60 & 1.00 & Train calculus & & \\
\hline
\end{tabular}


Table 5 : Estimates of specification (3.2.), Dependant variable: test scores.

Deaton errors-in-variables estimator for a small number of time periods, 90 percent of sample bootstrap. 500 iterations.

\begin{tabular}{|c|c|c|c|c|c|}
\hline & \multicolumn{2}{|c|}{ Reading } & \multicolumn{3}{|c|}{ Maths } \\
\hline & $2.5 \mathrm{Q}$ & Median 97.5Q & $2.5 \mathrm{Q}$ & Median & $97.5 Q$ \\
\hline $\begin{array}{l}\text { Home variables } \\
\text { Number of books } \\
\text { Computer at home } \\
\end{array}$ & $\begin{array}{c}-179.98 \\
387.08 \\
\end{array}$ & $\begin{array}{rr}44.80 & 233.74 \\
\mathbf{5 5 7 . 9 2} & 923.59 \\
\end{array}$ & $\begin{array}{l}-920.19 \\
646.65 \\
\end{array}$ & $\begin{array}{r}-216.16 \\
\mathbf{9 8 0 . 9 0} \\
\end{array}$ & $\begin{array}{c}26.8 \\
2363.9 \\
\end{array}$ \\
\hline $\begin{array}{l}\text { ICT in school } \\
\text { Teacher uses internet } \\
\text { Teacher uses computer } \\
\text { Computer lab in school }\end{array}$ & $\begin{array}{c}132.93 \\
26.11 \\
-151.14\end{array}$ & \begin{tabular}{cc|}
$\mathbf{1 6 7 . 0 0}$ & 216.98 \\
$\mathbf{4 4 . 3 0}$ & 75.95 \\
$-\mathbf{- 7 4 . 8 6}$ & -33.80 \\
\end{tabular} & $\begin{array}{c}39.36 \\
27.92 \\
-530.59\end{array}$ & $\begin{array}{c}89.97 \\
52.46 \\
-197.35 \\
\end{array}$ & $\begin{array}{r}204.8 \\
142.8 \\
-115.5 \\
\end{array}$ \\
\hline $\begin{array}{l}\text { School infrastructure } \\
\text { Sciencelab in school } \\
\text { Sport facilities } \\
\text { Library } \\
\text { Student teacher ratio } \\
\end{array}$ & $\begin{array}{l}17.58 \\
-76.48 \\
14.57 \\
-1.90 \\
\end{array}$ & \begin{tabular}{cc|}
$\mathbf{7 0 . 0 4}$ & 123.96 \\
-12.77 & 36.67 \\
$\mathbf{6 2 . 9 0}$ & 117.97 \\
0.42 & 2.19 \\
\end{tabular} & $\begin{array}{c}-1.82 \\
-87.98 \\
45.54 \\
0.80 \\
\end{array}$ & $\begin{array}{c}48.07 \\
-12.30 \\
\mathbf{8 5 . 1 5} \\
\mathbf{2 . 4 0}\end{array}$ & $\begin{array}{c}276.7 \\
37.2 \\
156.6 \\
8.2\end{array}$ \\
\hline $\begin{array}{l}\text { School human resources } \\
\text { Wage director } \\
\text { Teacher university degree } \\
\text { On the job training }\end{array}$ & $\begin{array}{c}7.65 \\
-10.16 \\
75.01 \\
\end{array}$ & \begin{tabular}{cc|}
$\mathbf{1 3 . 0 6}$ & 19.83 \\
30.36 & 70.72 \\
$\mathbf{1 0 7 . 5 1}$ & 168.28 \\
\end{tabular} & $\begin{array}{r}13.00 \\
-31.98 \\
35.86 \\
\end{array}$ & $\begin{array}{r}19.42 \\
-0.49 \\
77.01 \\
\end{array}$ & $\begin{array}{c}45.6 \\
86.2 \\
206.5\end{array}$ \\
\hline $\begin{array}{l}\text { Educational policy } \\
\text { Library policy } \\
\text { Transport policy } \\
\text { Educ TV policy }\end{array}$ & $\begin{array}{r}-21.91 \\
-65.61 \\
34.59\end{array}$ & \begin{tabular}{cc|}
14.54 & 46.79 \\
0.80 & 50.47 \\
72.35 & 133.48
\end{tabular} & $\begin{array}{c}-100.60 \\
53.63 \\
110.89\end{array}$ & $\begin{array}{c}5.48 \\
100.22 \\
171.99\end{array}$ & $\begin{array}{c}35.4 \\
253.5 \\
445.3\end{array}$ \\
\hline
\end{tabular}

In bold estimates are significantly different from zero at a 95 percent level of confidence. 
Table 6 : Specification (3.2), with and without cohort size weights, 500 iterations, 90 percent of sample bootstrap. Dependant variable: Portuguese test scores

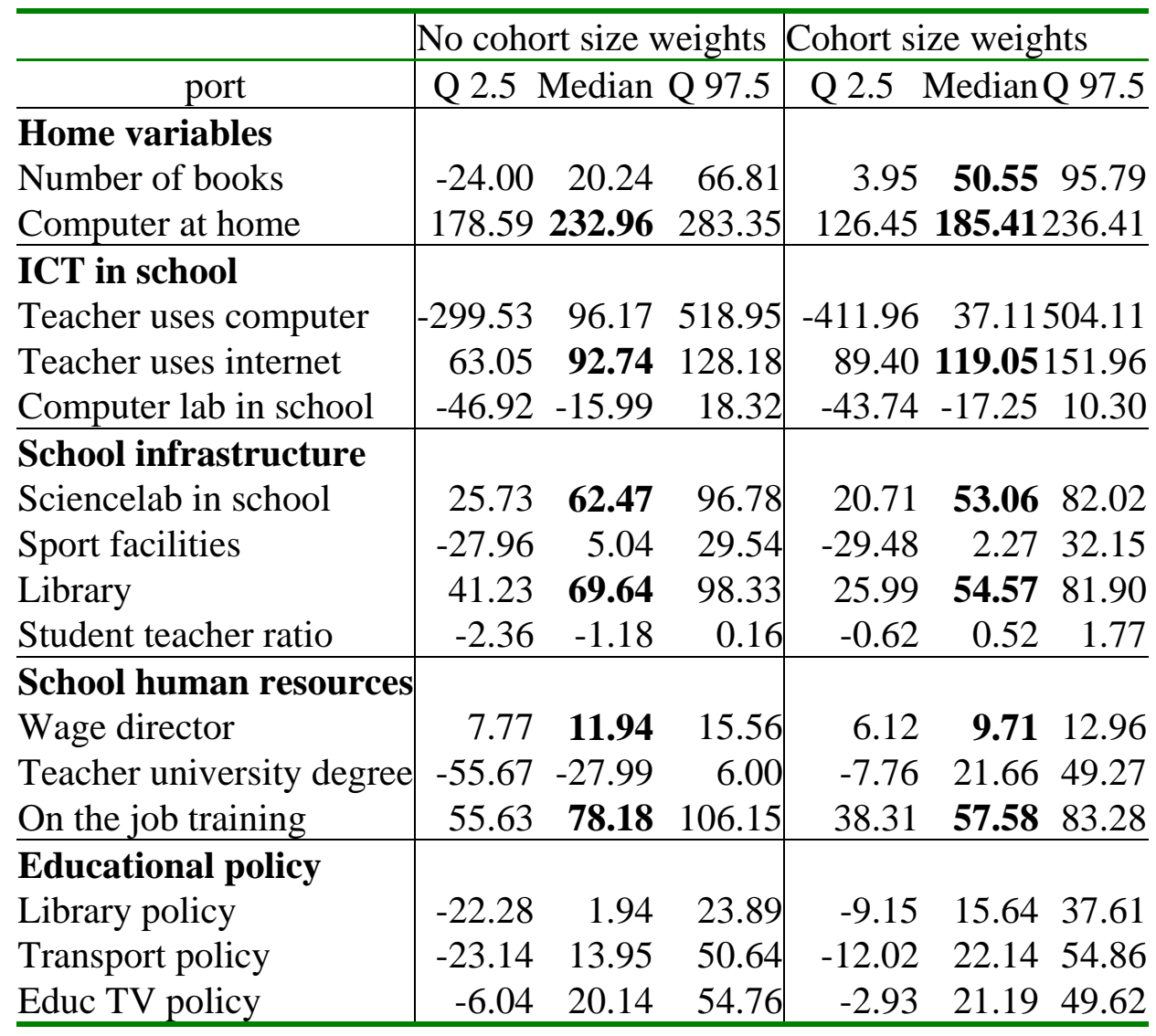

In bold estimates are significantly different from zero at a 95 percent level of confidence. 
Table 7 : Specification (3.2), with and without cohort size weights, 500 iterations, 90 percent of sample bootstrap. Dependant variable: Maths test scores

\begin{tabular}{|c|c|c|c|c|c|c|}
\hline OLS I & No coho & rt size we & eights & Cohort si & size weigh & \\
\hline & Q 2.5 & Median & Q 97.5 & Q 2.5 & Median & Q 97.5 \\
\hline $\begin{array}{l}\text { Jome variables } \\
\text { Jumber of books } \\
\text { Lomputer at home }\end{array}$ & $\begin{array}{l}-50.02 \\
150.89 \\
\end{array}$ & $\begin{array}{r}-9.84 \\
215.46 \\
\end{array}$ & $\begin{array}{rr}4 & 26.55 \\
6 & 286.76 \\
\end{array}$ & $\begin{array}{l}-58.21 \\
139.65 \\
\end{array}$ & $\begin{array}{l}-24.42 \\
199.90 \\
\end{array}$ & $\begin{array}{r}9.21 \\
251.09 \\
\end{array}$ \\
\hline $\begin{array}{l}\text { ICT in school } \\
\text { Teacher uses computer } \\
\text { Teacher uses internet } \\
\text { Computer lab in school }\end{array}$ & $\begin{array}{r}-153.81 \\
-3.45 \\
-40.68 \\
\end{array}$ & $\begin{array}{r}177.90 \\
22.27 \\
-6.96 \\
\end{array}$ & $\begin{array}{r}509.49 \\
7 \\
47.99 \\
5 \\
16.85 \\
\end{array}$ & \begin{tabular}{|r}
-273.29 \\
12.85 \\
-37.91 \\
\end{tabular} & $\begin{array}{r}361.91 \\
36.23 \\
-15.71 \\
\end{array}$ & $\begin{array}{r}766.44 \\
56.96 \\
1 \quad 2.40 \\
\end{array}$ \\
\hline $\begin{array}{l}\text { Sciencelab in school } \\
\text { Sport facilities } \\
\text { Library } \\
\text { Student teacher ratio }\end{array}$ & $\begin{array}{r}-24.10 \\
7.97 \\
18.55 \\
0.47\end{array}$ & $\begin{array}{r}1.95 \\
28.47 \\
38.34 \\
1.37\end{array}$ & $\begin{array}{r}24.79 \\
48.34 \\
56.57 \\
2.33\end{array}$ & $\begin{array}{r}-50.51 \\
-28.90 \\
42.30 \\
-0.41\end{array}$ & $\begin{array}{r}-25.01 \\
-8.77 \\
\mathbf{5 8 . 8 1} \\
\mathbf{0 . 4 2} \\
\end{array}$ & $\begin{array}{r}-3.67 \\
12.59 \\
77.35 \\
1.44\end{array}$ \\
\hline $\begin{array}{l}\text { School human resources } \\
\text { Wage director } \\
\text { Teacher university degree } \\
\text { On the job training }\end{array}$ & $\begin{array}{r}4.88 \\
-20.87 \\
-29.57 \\
\end{array}$ & $\begin{array}{r}7.99 \\
4.53 \\
-2.02 \\
\end{array}$ & $\begin{array}{l}10.90 \\
20.16 \\
23.22\end{array}$ & $\begin{array}{r}3.58 \\
-44.00 \\
12.49 \\
\end{array}$ & $\begin{array}{r}6.72 \\
-26.92 \\
32.32 \\
\end{array}$ & $\begin{array}{r}9.27 \\
-11.33 \\
51.07 \\
\end{array}$ \\
\hline $\begin{array}{l}\text { Educational policy } \\
\text { Library policy } \\
\text { Transport policy } \\
\text { Educ TV policy } \\
\end{array}$ & $\begin{array}{r}30.53 \\
13.07 \\
-8.14 \\
\end{array}$ & $\begin{array}{l}\mathbf{5 1 . 3 7} \\
\mathbf{3 6 . 2 7} \\
13.10\end{array}$ & $\begin{array}{l}65.70 \\
66.47 \\
31.57\end{array}$ & $\begin{array}{l}11.82 \\
20.79 \\
16.57\end{array}$ & $\begin{array}{l}28.00 \\
49.09 \\
36.94\end{array}$ & $\begin{array}{l}40.88 \\
76.03 \\
54.77 \\
\end{array}$ \\
\hline
\end{tabular}

In bold estimates are significantly different from zero at a 95 percent level of confidence. 
Table 8: Teaching methods (only years 2001 and 2003)

Deaton estimator for a small number of time periods, 500 iterations, 90 percent of sample bootstrap Dependant variable: Maths test scores

\begin{tabular}{l|ccc|ccc}
\hline & Q05 & MEDIAN & Q95 & Q05 & MEDIAN Q95 \\
\hline Home variables & & & & & & \\
Number of books & -4435 & 204.5 & 6729 & -6944 & -465.10 & 8827 \\
Computer at home & -10326 & 1693 & 10254 & -11771 & 2240.60 & 11258 \\
\hline ICT in school & & & & & & \\
Teacher uses internet & -1221 & 289.9 & 1739 & -1221 & 308.60 & 1291 \\
School has computer lab & -2142 & -350.9 & 1961 & -2177 & -414.30 & 2070 \\
\hline School infrastructure & & & & & & \\
School has a science lab & -788 & 16.6 & 557 & -1480 & 136.80 & 1140 \\
Sports facilities & -661 & 63.2 & 794 & -888 & -48.60 & 894 \\
School has a library & -28 & -0.7 & 28 & -1221 & 320.40 & 1414 \\
Student teacher ratio & -7 & -2.2 & 5 & -36 & -0.80 & 41 \\
\hline School human resources & & & & & & \\
Wage director & -50 & 12.2 & 54 & -160 & 16.80 & 117 \\
University graduate teacher & -1270 & -128 & 530 & -772 & -148.90 & 475 \\
On the job trained teacher & -205 & 110.1 & 494 & -1105 & 112.80 & 1082 \\
\hline Educational policy & & & & & & \\
Library policy & -411 & 56.9 & 544 & -851 & 8.00 & 1018 \\
Transport policy & -1582 & -104.9 & 1113 & -831 & -86.10 & 452 \\
Educational tv policy & -861 & 198.1 & 1078 & -1018 & 186.60 & 973 \\
\hline Teaching methods & & & & & & \\
Questions of pupil interest & & & & -581 & 34.00 & 767 \\
Solve problems & & & & -3559 & 534.10 & 2701 \\
Calculus & & & & -181.20 & 3809 \\
\hline
\end{tabular}


Table 9: Teaching methods (only years 2001 and 2003)

Deaton estimator for a small number of time periods, 500 iterations, 90 percent of sample bootstrap Dependant variable: Portuguese test scores

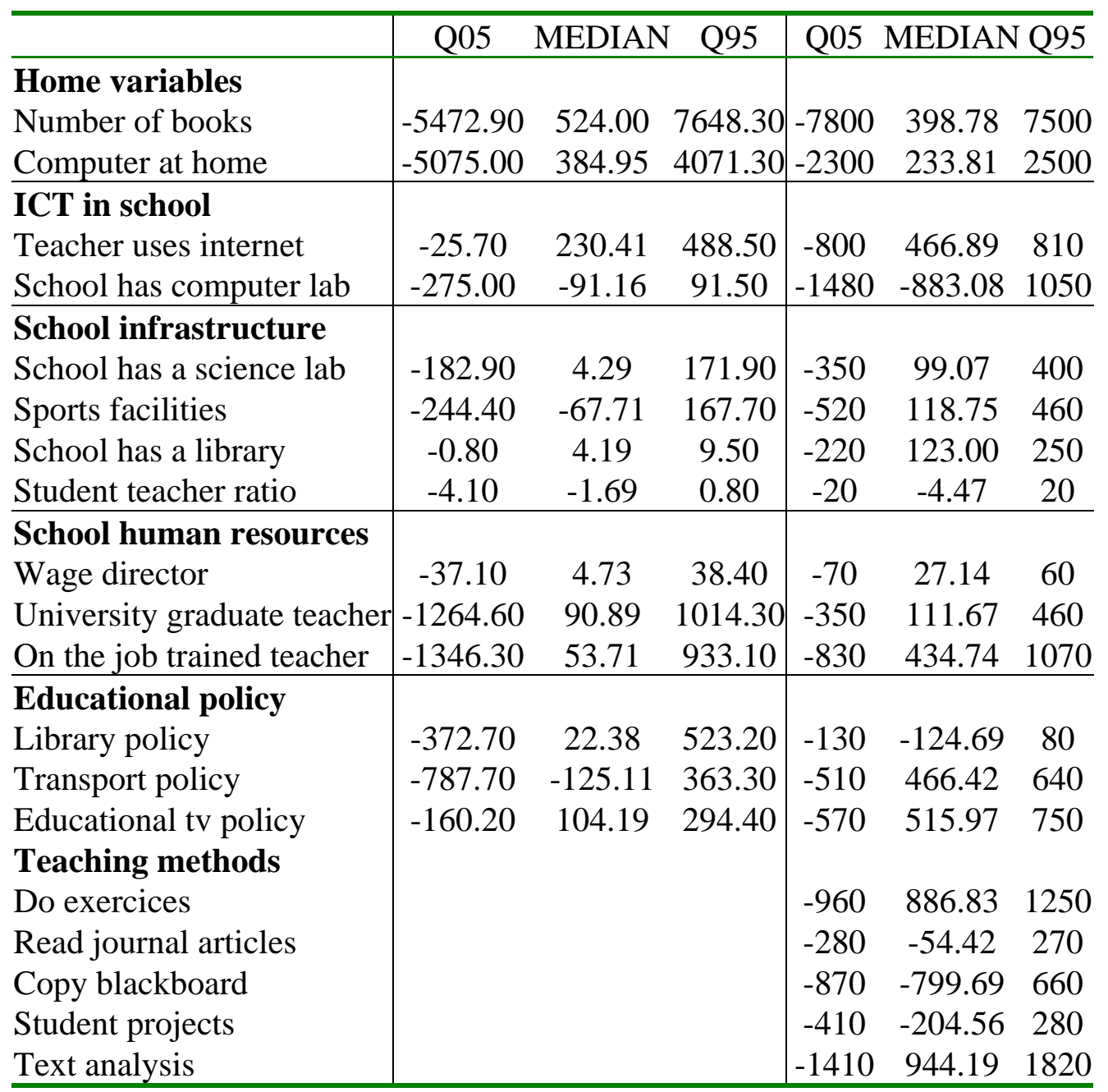




\section{Bibliography}

Angrist J. and Lavy V.(2002), 'New evidence on classroom computers and pupil learning', The Economic Journal No.112, pp.735-765.

Banerjee A., Cole S., Duflo E. and Linden L. (2004), 'Remedying education: Evidence from two randomised experiments in India', mimeo, MIT.

Barrow L. and Rouse C. (2005), 'Causality, causality, causality: the view of education inputs and outputs from economics',

Borman G. and Rachuba L.(2001), 'Evaluation of the scientific learning corporation's Fast For Word computer-based training program in the Baltimore city's public schools', a report prepared for the Abell Foundation.

Cameron A. and Trivedi P.(2005), 'Measurement Error Models', Chapter 26 in: Micro Econometrics: methods and applications. .

Deaton A.(1985), 'Panel data from a time series of cross-sections', Journal of Econometrics 30. pp.109-126.

Fuchs and Woessman (2004), 'Computers and student learning: bivariate and multivariate evidence on the availability of computers at home and at school', CESifo Working Paper 1321.

Goolsbee A. and Guryan J.(2002), 'The impact of internet subsidies in public schools’, NBER Working Paper 9090.

Grün C.(2003), 'Racial and gender wage differentials in South Africa : what can cohort data tell?’, Munich Economics Discussion Paper 2003-21.

Guimaraes De Castrov M., 'The National Basic Education Evaluation System-SAEB', Presentation at the 6th Meeting of the education partnership implementation commission, Atlanta, USA.

Leuven E., Lindahl M., Oosterbeek H. and Webbink D.(2004), 'The effect of extra funding for disadvantaged pupils on achievement', IZA Discussion Paper 1122.

Liao Y.(1992), 'Effects of computer assisted instruction on cognitive outcomes. A meta analysis', Journal of Research on Computing in Education, No.24: 367-380. 
Kirkpatrick H. and Cuban L. (1998), 'Computers make kids smarter-right? , TECHNOS Quarterly for Education and Technology 7(2): 1-11.

Machin S., McNally S., and Silva O.(2005), 'New Technology in Schools: Is There a Payoff ?’, IZA Discussion Paper No.2234.

Nimubona A-D. (2002), 'Analyse de la mobilité intergénérationnelle en Afrique du Sud', Master thesis Ecole des hautes études commerciales de Montréal (HEC), Institut de Recherche en Economie Contemporaine (IREC), Montréal.

Paxson Ch. and Waldfogel J. (1999), 'Parental resources and child abuse and neglect', American Economic Review No. 89.

Propper C., Rees H., and Green K. (2001), 'The demand for private insurance in the UK : a cohort analysis', Economic Journal 111.

Rouse C. and Krueger A. (2004), 'Putting computerized instruction to the test: a randomised evaluation of a 'Scientifically-Based' reading program', Economics of Education Review 23(4), p.323-338.

Skinner B.F.(1958), 'Teaching machines', Science, New Series, Vol.128 No.3330, pp.969-977.

Taylor K. (2002), 'The impact of technology and trade upon the returns to education and occupation', Applied Economics 34.

Twining P. (2002), 'ICT in schools. Estimating the level of investment', MeD8 Report No.02.01. Online at www.meD8.info.

Verbeek M.(1996), 'Pseudo panel data' in: The Econometrics of Panel Data: Handbook of the theory with applications, Matyas L. and Sevestre P., Eds, Kluwer Academic Publishers: 280-292.

Verbeek M. and Nijman T. (1993), 'Minimum MSE estimation of a regression model with fixed effects from a series of cross-sections', Journal of Econometrics 59: 125-36.

Woolridge J. (2002), Econometric analysis of cross section and panel data, MIT. 